\title{
Objective and subjective in vivo comparison of two emollient products
}

This article was published in the following Dove Press journal:

Clinical, Cosmetic and Investigational Dermatology

7 August 2012

Number of times this article has been viewed

\author{
Jasmina Djokic-Gallagher' \\ Phil Rosher' \\ Jennine Walker' \\ Valerie Hart ${ }^{2}$ \\ 'Research and Development \\ Department, Dermal Laboratories \\ Ltd, Hitchin, ${ }^{2}$ Reading Scientific \\ Services Ltd, Reading Science Centre, \\ Whiteknights Campus, University \\ of Reading, Reading, UK
}

Correspondence: Jasmina Djokic-Gallagher Tatmore Place, Hitchin SG4 7QR, UK Tel +44 I4 62458866

Fax +44 I4 62438707

Email jasmina.gallagher@dermal.co.uk
Background: Few studies have directly compared the effectiveness of different emollients in vivo, and the important matter of patient preference is generally overlooked.

Methods: We report the results of an assessor-blinded, bilateral, concurrent comparison of two emollient pharmaceutical presentations, ie, Doublebase gel (DB) and Aqueous cream BP (AC), applied by 20 participants three times daily for 7 consecutive days. The primary efficacy endpoint was cumulative improvement in skin hydration measured by corneometry on days 1, 3, and 5 immediately before the first application and approximately 2 hours after the third application of the day. Secondary endpoints were investigator assessment of skin condition at these time points and participant assessment of product acceptability at the end of the study.

Results: Both products increased skin hydration, but the effect of $\mathrm{AC}$ was relatively modest, with morning values readily returning to pretreatment levels. Hydration levels were higher for DB gel, maintained at all time points, and showed stepwise, cumulative increases over the 7 days of use. Overall patient satisfaction scores were higher for DB gel, and especially for "consistency," "ease of use," and "ease of absorption into the skin." Eighty-five percent of participants expressed a desire to use DB gel again as compared with $40 \%$ for AC.

Keywords: Doublebase, Aqueous cream, hydration, emollient, comparison

\section{Introduction}

In the UK, the National Institute of Clinical Excellence (NICE) clinical guidance on the management of atopic eczema in children from birth to the age of 12 years establishes emollient therapy as the treatment modality that should underpin all else. ${ }^{1}$ The guidance recommends continuing emollient therapy even when the skin appears healthy. Health care professionals are advised to offer children with atopic eczema a regime of "complete" emollient therapy involving a choice of nonperfumed emollients to use every day, both as leave-on moisturizers and as soap substitutes for routine washing and bathing.

Emollient formulations suitable for such use typically contain both oily occlusive substances, such as petrolatum, paraffin, or mineral oil, which form a waterimpermeable film over the skin to decrease evaporation of physiological water from beneath, and humectant substances, such as glycerol and urea, which attract water to the skin..$^{2-5}$ However, in order to encourage compliance with treatment, it is also crucially important that these products are formulated in such a way that their physical characteristics render them appealing for patients to use over large surface areas and for long periods of time. ${ }^{6}$ 
Ideally, emollients should exert their skin softening and moisturizing effects within the upper layers of the skin. Thick, greasy ointments undoubtedly exhibit good emollient characteristics, but are not very popular with patients because they are not well absorbed into the skin and leave an oily residue which can feel uncomfortable and has a tendency to soil clothing and bed linen., ${ }^{4,7}$ More popular emollients are formulated as oil-in-water creams or lotions to make them "feel" lightweight and to encourage better absorption into the skin. ${ }^{8}$ However, these dosage forms are less effective than ointments because of their lower oil content, resulting in reduced occlusive capability. ${ }^{9}$ Moreover, cream and lotion formulations exhibit poor substantivity and have a tendency to be easily rubbed off onto clothing, so require more frequent reapplication than would be practicable for many patients. Emollient gels are alternative pharmaceutical presentations for atopic eczema sufferers and usually contain high concentrations of oily ingredients in semisolid aqueous systems. To achieve maximum benefit, some of these gels, just like other emollients, need to be applied regularly and frequently.

Performance evaluation methods for emollients and moisturizers are mainly focused on sensory aspects, skin visual appearance, perceived efficacy, and measurements of skin barrier hydration and integrity. ${ }^{5}$ However, few studies have involved patients directly comparing the effectiveness of different emollients by using them concurrently or under conditions mimicking normal therapeutic use, ${ }^{9,10}$ and the important matter of patient preference is generally overlooked altogether. Here we report the results of a study comparing simultaneous use of a proprietary emollient gel formulation, Doublebase gel (DB), with that of Aqueous cream BP (AC). The latter, although originally introduced for use primarily as a soap substitute, is commonly recommended in the UK for continuous use as a leave-on moisturizer owing to its relatively low cost. The performance of these two formulations are compared in this study using objective corneometry measurements of cumulative skin hydration, investigator assessment of skin condition, and subjective participant assessment of product acceptability.

\section{Materials and methods}

The study design comprised an assessor-blind, bilateral, concurrent comparison of AC and DB gel (Dermal Laboratories Ltd, Hitchin, UK) applied to the lower legs in 20 female patients aged 24-65 years with a history of dry skin. The study was conducted with full ethics approval (Reading Independent Ethics Committee, Reading, UK). Written informed consent was obtained from all subjects and witnessed. Exclusion criteria were: significant concurrent illness or skin disease; history of allergy relevant to the test products or their ingredients; use of any topical or systemic treatment likely to affect skin response; visible skin abnormality or excessive hair growth likely to interfere with measurements; irritation, tattoos, scars, or birthmarks at the test measurement sites; participation in any other study presently or within the past 3 months; and breastfeeding and pregnancy. Also, removal of leg hair was not allowed within 48 hours prior to study participation and for the duration of the study.

Both test products are white semisolids, and in the study were presented, for blinding purposes, in identical $500 \mathrm{~g}$ bottles fitted with metered pump dispensers delivering approximately $1.2 \mathrm{~mL}$ per depression. Left/right leg treatment allocation was prerandomized and hidden from the investigators. The participants themselves were aware of the differing "feels" of the two emollients, but did not know which product was which (both formulations were referred to in all trial paperwork and communications simply as "products"). The treatment regimen required participants to massage one pump depression of each product gently into each assigned lower leg at approximately 9 am, noon, and $5 \mathrm{pm}$ for seven consecutive days (days 1-7 inclusive) thus mimicking normal clinical recommendations. The application area was kept consistent between left/right legs. The bottles were weighed before and after study completion to determine the total quantities actually used.

On alternate days (1, 3, and 5), the participants attended the study center for objective corneometer measurements and subjective investigator assessments of skin condition. These evaluations were repeated for each lower leg both immediately prior to the first application of the day (with measurements on day 1 defined as "baseline" values) and approximately 2 hours after the third application of the day. Final measurements were repeated on day 8 between 9 am and $10 \mathrm{am}$. There were no test center visits on intervening days $(2,4,6$, and 7). Participants maintained a daily record of each treatment and, on day 8 , completed a product satisfaction questionnaire.

Participants were asked to refrain from bathing, showering, or washing their lower legs at all on skin assessment days $(1,3,5$, and 8$)$, but were invited to do so whenever and as often as they liked on intervening days $(2,4,6$, and 7 , always leaving a delay of at least 2 hours after the most recent emollient application of the day). Thus, the study was designed to encourage bathing, showering, or washing at any convenient time prior to the morning measurements 
on days 3,5 , and 8 , in order to monitor the potentially deleterious effect of washing off earlier applications of the emollients, and to prevent such occurring during the course of the measurement days. Participants were not permitted to use any other skin moisturizer on their legs at any time during their participation in the study, nor any other topical or systemic medication considered by the chief investigator to potentially interfere with the study outcome. Details of any medication being used by participants prior to and during the study were recorded.

\section{Corneometer measurements}

Noninvasive measurements of stratum corneum hydration were performed using a standard corneometric technique. ${ }^{11,12}$ The corneometer measures the electrical capacitance of the stratum corneum, and is a well established technique for determining skin hydration levels. ${ }^{13,14}$ Measurements were performed using a Multiprobe Adapter MPA5 with a Corneometer CM825 probe (Courage and Khazaka, Koln, Germany). All measurements were the mean of triplicate determinations performed at the same skin sites on the lower legs located, for each participant, by a reusable template.

The corneometer values are expressed in arbitrary units, and tabulated for each emollient as the mean and standard deviation for both the actual mean corneometer value at each time point, and for the mean corneometer value at each time point minus the corresponding mean treatment value at baseline (to provide a summary measurement of cumulative improvement from baseline over time). The latter was predesignated as the primary endpoint and analyzed using Wilcoxon's rank-sum test and PROC NPAR1WAY, with significant differences between the emollients declared at the $5 \%$ level.

\section{Subjective assessment of skin condition}

The investigator assessed lower leg skin dryness and erythema separately under standard conditions of illumination using a hand-held lamp fitted with an incandescent blue daylight bulb. A four-point scoring system was used whereby $0=$ none, $1=$ slight, $2=$ moderate, and $3=$ severe. These data are tabulated, for each emollient, as the mean and standard deviation at each time point. The data were analyzed using the Student's $t$-test and significance was declared at the $5 \%$ level.

\section{Product satisfaction questionnaire}

The day 8 product satisfaction questionnaire involved participants answering the following questions: how much they liked/disliked each product, using a five-point rating score, whereby 1 = dislike strongly, 2 = dislike slightly, 3 = neither like nor dislike, 4 = like slightly, and $5=$ like strongly; and for each of the following questions, using a five-point rating score, whereby $1=$ disagree strongly, $2=$ disagree slightly, 3 = neither agree nor disagree, 4 = agree slightly, and $5=$ agree strongly, whether each product was soothing, reduced any itching, made their skin feel smoother and moisturized, was easy to apply and easily absorbed into the skin, if each product had a pleasant consistency and smell, and whether or not they would like to use each product again. To calculate arithmetical mean scores for each question, the scores (1-5) were multiplied by their frequencies and the product was divided by the number of participants. The data were analyzed using the Student's $t$-test, with significant differences between the emollients declared at the 5\% level.

\section{Results}

All 20 participants screened entered and completed the study. Eight participants used concomitant medication, in each case taking only orally administered treatments, such as contraceptive hormone treatment and antihypertensives or diuretics, which were considered unlikely to interfere with the study outcome. The quantities of the two test emollients used were broadly consistent with the intended dosage, and were well balanced for the individual patients.

\section{Corneometer measurements}

Results of the corneometer assessments are shown in Table 1. Capacitance levels were well balanced between study treatment sites at baseline, and increased by the end of the first day of emollient usage. Thereafter, corneometer readings taken at the start of the measurement days immediately before the first application of the day were lower than the maximum reached by the end of the previous measurement day. However, whereas corneometer readings for AC returned

Table I Corneometer measurements of skin capacitance $(n=20)$

\begin{tabular}{lll}
\hline & \multicolumn{2}{l}{$\begin{array}{l}\text { Corneometer measurements } \\
\text { (mean } \pm \text { SD) }\end{array}$} \\
\cline { 2 - 3 } & Doublebase gel & Aqueous cream \\
\hline Baseline (start day I) & $34.54 \pm 9.27$ & $36.59 \pm 10.23$ \\
End day I & $48.28 \pm 14.22$ & $43.80 \pm 13.12$ \\
Start day 3 & $39.98 \pm 10.22$ & $36.73 \pm 8.10$ \\
End day 3 & $49.85 \pm 8.78$ & $41.14 \pm 10.10$ \\
Start day 5 & $44.16 \pm 9.52$ & $38.90 \pm 11.45$ \\
End day 5 & $49.42 \pm 8.32$ & $39.17 \pm 8.39$ \\
Start day 8 & $45.47 \pm 7.63$ & $36.29 \pm 7.77$ \\
\hline
\end{tabular}

Abbreviation: SD, standard deviation. 
each morning to around baseline, elevated DB gel readings were maintained and showed a stepwise cumulative increase of more than 10 units over 7 days of use. The corresponding mean differences from baseline (ie, improvement in skin hydration) are summarized in Table 2. The improvements in skin hydration levels in favor of DB gel were statistically significant $(P \leq 0.05)$ at all 'end of day' time points and for readings at the 'start of day' on days 5 and 8 .

\section{Subjective assessment of skin condition}

Results for visual assessment of skin dryness are summarized in Table 3. The mean scores were well balanced at baseline and generally improved over time, with no statistically significant differences between the two products $(P=0.577)$. No erythema was observed.

\section{Product satisfaction scores}

Results of the product satisfaction assessments are presented in Table 4. The scores for both products generally indicated varying levels of satisfaction (as opposed to dissatisfaction, ie, mean scores were $>3$ ) for most criteria, with notable exceptions for AC only, being "ease of application" (score 2.60), "absorption into the skin" (score 2.15), and "consistency" (score 2.95). Corresponding scores for the DB gel were appreciably higher $(4.65,4.30$, and 4.40 , respectively), such that satisfaction levels in favor of the DB gel were highly statistically significant $(P<0.0001)$ for each of these parameters. For participant responses to the question regarding how much they liked or disliked the products overall, the mean score for AC was 3.05 (suggesting that overall it was generally neither liked nor disliked), whereas the score for DB gel was 4.15, and the difference between these was highly statistically significant $(P=0.002)$. Seventeen participants $(85 \%)$ said they would like to use DB gel again as compared with eight participants (40\%) who said they would like to use AC again.

Table 2 Adjusted corneometer measurements of skin capacitance

\begin{tabular}{lcll}
\hline & \multicolumn{2}{l}{$\begin{array}{l}\text { Difference from baseline corneometry } \\
\text { measurements (mean } \pm \text { SD) }\end{array}$} \\
\cline { 2 - 4 } & $\begin{array}{l}\text { Doublebase } \\
\text { gel }\end{array}$ & $\begin{array}{l}\text { Aqueous } \\
\text { cream }\end{array}$ & $\begin{array}{l}\text { P value Wilcoxon's } \\
\text { rank-sum test }\end{array}$ \\
\hline End day I & $13.74 \pm 10.26$ & $7.21 \pm 12.74$ & $\mathbf{0 . 0 4 0 I}$ \\
Start day 3 & $5.44 \pm 8.06$ & $0.14 \pm 9.4 I$ & 0.0938 \\
End day 3 & $15.31 \pm 8.53$ & $4.54 \pm 12.35$ & $\mathbf{0 . 0 0 6 0}$ \\
Start day 5 & $9.62 \pm 6.32$ & $2.31 \pm 12.97$ & $\mathbf{0 . 0 0 2 7}$ \\
End day 5 & $14.88 \pm 7.26$ & $2.58 \pm 7.34$ & $\mathbf{0 . 0 0 0 I}$ \\
Start day 8 & $10.92 \pm 9.89$ & $-0.3 \pm 11.76$ & $\mathbf{0 . 0 0 4 3}$ \\
\hline
\end{tabular}

Notes: Bold denotes statistically significant differences. Abbreviation: SD, standard deviation.
Table 3 Daily mean erythema and dryness scores

\begin{tabular}{|c|c|c|c|c|}
\hline & \multicolumn{2}{|c|}{$\begin{array}{l}\text { Erythema } \\
(\text { mean } \pm S D)\end{array}$} & \multicolumn{2}{|c|}{$\begin{array}{l}\text { Dryness } \\
(\text { mean } \pm \text { SD) }\end{array}$} \\
\hline & $\begin{array}{l}\text { Double- } \\
\text { base gel }\end{array}$ & $\begin{array}{l}\text { Aqueous } \\
\text { cream }\end{array}$ & $\begin{array}{l}\text { Double- } \\
\text { base gel }\end{array}$ & $\begin{array}{l}\text { Aqueous } \\
\text { cream }\end{array}$ \\
\hline Baseline & 0 & 0 & $1.25 \pm 0.64$ & $1.25 \pm 0.64$ \\
\hline End day I & 0 & 0 & $0.20 \pm 0.4 \mathrm{I}$ & $0.20 \pm 0.4 I$ \\
\hline Start day 3 & 0 & 0 & $0.35 \pm 0.49$ & $0.4 \pm 0.50$ \\
\hline End day 3 & 0 & 0 & 0 & 0 \\
\hline Start day 5 & 0 & 0 & 0 & $0.05 \pm 0.22$ \\
\hline End day 5 & 0 & 0 & 0 & 0 \\
\hline Start day 8 & 0 & 0 & $0.15 \pm 0.37$ & $0.20 \pm 0.4 I$ \\
\hline
\end{tabular}

Abbreviation: SD, standard deviation.

This difference in favor of DB gel was also highly statistically significant $(P=0.0038)$.

\section{Discussion}

Emollients are regularly used in the treatment of dry, scaly skin associated with atopic dermatitis. However, despite widespread acceptance of the importance of emollient therapy, there remains a lack of good quality evidence on product effectiveness or whether one particular product is better than another. ${ }^{15}$ Not surprisingly, there is a common expectation among health care professionals that all topical emollient preparations should possess similar hydration properties and perform equally well.

The primary objective of this study was to compare the cumulative skin hydration action of DB gel versus AC over 7 days of treatment. An application frequency of three times daily was selected for both products in order to enable direct comparison and to meet the NICE requirement for frequent emollient application. Although both products increased skin moisturization levels, the effect for AC was relatively modest, with values returning to baseline by each morning measurement when washing/showering had been permitted in the intervening periods. With DB gel, the elevated baselineadjusted hydration levels were significantly higher than for $\mathrm{AC}$, and were still evident by the morning measurements and showed cumulative increases over time. From the end of day 3 measurement, and at all time points thereafter, the mean improvements in skin moisturization from baseline for DB gel were 9.62 to 15.31 units, whereas for AC, improvement values were below 5 units at all these time points (ranging from -0.30 to 4.54 units).

Because the two products contain similar levels of oily ingredients (Table 5), it would be reasonable to expect comparable effects on skin hydration. The measured difference in the performance of the two products could be attributed 
Table 4 Cosmetic acceptability of the emollients

\begin{tabular}{|c|c|c|c|}
\hline & $\begin{array}{l}\text { Doublebase gel } \\
\text { (mean } \pm \text { SD) }\end{array}$ & $\begin{array}{l}\text { Aqueous cream } \\
\text { (mean } \pm \text { SD) }\end{array}$ & $\begin{array}{l}P \text { value } \\
\text { t-test }\end{array}$ \\
\hline "Product liked" & $4.15 \pm 0.88$ & $3.05 \pm 1.10$ & 0.0020 \\
\hline "Product was soothing" & $3.68 \pm 1.11$ & $3.47 \pm 0.90$ & 0.3306 \\
\hline "Product reduced the itching" & $3.45 \pm 1.21$ & $3.55 \pm 1.21$ & 0.6761 \\
\hline "Product made skin feel smoother" & $4.40 \pm 0.50$ & $4.40 \pm 0.60$ & 1.0000 \\
\hline "Product made skin feel softer" & $4.40 \pm 0.68$ & $4.35 \pm 0.75$ & 0.7894 \\
\hline "Product made skin feel moisturized" & $4.10 \pm 1.17$ & $4.00 \pm 1.08$ & 0.5409 \\
\hline "Product was easy to apply" & $4.65 \pm 0.59$ & $2.60 \pm 1.47$ & $<0.000$ I \\
\hline "Product was easily absorbed into the skin" & $4.30 \pm 1.22$ & $2.15 \pm 1.14$ & $<0.0001$ \\
\hline "Product had pleasant consistency" & $4.40 \pm 0.75$ & $2.95 \pm 1.15$ & $<0.0001$ \\
\hline "Product smell was acceptable" & $3.61 \pm 1.20$ & $3.50 \pm 1.04$ & 0.3313 \\
\hline Would you like to use product again & DB gel & AC & $\begin{array}{l}P \text { value hypothesis } \\
\text { test on percentages }\end{array}$ \\
\hline No & 3 & 12 & 0.0038 \\
\hline Yes & 17 & 8 & \\
\hline
\end{tabular}

Notes: Bold denotes statistically significant differences.

to the presence of glycerol (propane-1,2,3-triol), a well known humectant, in the DB gel formulation. Glycerol has a tendency to accumulate within the entire thickness of the stratum corneum, ${ }^{16}$ and its three hydrophilic hydroxyl groups have the ability to bind and retain water, thus providing enhanced skin hydration. ${ }^{17}$ Another possible explanation for the differences in their hydrating effects may stem from the way the two emulsions are formed. In the case of $\mathrm{AC}$, the high oil content is achieved by emulsifying the lipids into the aqueous phase using sodium lauryl sulfate and cetostearyl alcohol. This produces a stable emulsion which can be easily spread over the skin surface, but is prone to being easily removed by washing. For the DB gel, on the other hand, the lipid phase is emulsified and dispersed into a hydrogel base by incorporation of a hydrophobically modified carbopol resin. ${ }^{18,19}$ The carbopol acts as both a primary emulsifying agent and a viscosity modifier to form an oil-in-water gel structure. ${ }^{19}$ However, because the emulsifying properties of the polymer system are destroyed by electrolytes, ${ }^{20}$ the salts present on the surface of the skin are likely to cause irreversible separation of the oil and water phases of the DB gel during application. The lipid

Table 5 Composition of Doublebase gel and Aqueous cream BP

\begin{tabular}{ll}
\hline Doublebase gel (\%w/w) & Aqueous cream BP 2009 (\%w/w) \\
\hline Isopropyl myristate I5\% & White soft paraffin I5\% \\
Liquid paraffin I5\% & Liquid paraffin 6\% \\
Glycerol & Cetosteryl alcohol 8. I\% \\
Carbomer & Sodium lauryl sulfate \\
Sorbitan laurate & Phenoxyethanol \\
Triethanoloamine & Water \\
Phenoxyethanol & \\
Purified water & \\
\hline
\end{tabular}

phase is then left to form an occlusive barrier over the skin, which subsequently is much less readily re-emulsified and dispersed from the skin. This may explain why the elevated DB gel readings showed a stepwise, cumulative increase over 7 days of use despite intermittent bathing or washing. In contrast, skin hydration readings for $\mathrm{AC}$ each morning returned to around baseline.

Although the effectiveness of an emollient is of primary importance, compliance with treatment depends upon patient satisfaction with the physical characteristics of their chosen emollient. ${ }^{4}$ Patients will use emollients regularly for many years, but only if they like using them. ${ }^{21}$ In this study, participants rated DB gel significantly higher than $\mathrm{AC}$ with regard to ease of application, ease of absorption into the skin, and consistency (notably the scores for each of these characteristics were greater than 4.3). Commensurate with this was the significantly better "like/dislike" score of 4.15 for DB gel, indicating that participants were generally satisfied with it overall in comparison with AC, which scored 3.05, indicating a more indifferent rating. However, participants deemed both products to be equally good in terms of achieving softer, smoother, and more moisturized skin. No differences between the two products were observed regarding soothing and antipruritic properties or between their odors. Nevertheless, the most therapeutically relevant outcome was the percentage of participants who said they would use DB gel again (85\%) compared with AC (40\%). These results are consistent with the results of a formal preference evaluation reported by other investigators, ${ }^{22}$ who performed a questionnaire survey of 100 outpatients with eczema to evaluate six leading proprietary emollients and an ointment comprising a 50:50 mixture of white soft paraffin 
and liquid paraffin. They found DB gel to be the preferred choice, and the ointment, not surprisingly, was the least favorite. Eighty-one percent of the patients in that study said the emollient they liked the most was not the one they were currently being prescribed.

Prescribers tend to recommend emollient products that are deemed to be gentle on the skin and least likely to cause sensitivity problems. This is especially important when prescribing for patients with atopic dermatitis, in whom some ingredients can be notorious sensitizers..$^{9,23}$ In this regard, DB gel contains phenoxyethanol (a preservative) and triethanolamine (a crosslinking agent) which are potential skin sensitizers. The AC formulation contains phenoxyethanol and sodium lauryl sulfate (an anionic emulsifier). Like soaps and detergents, sodium lauryl sulfate has a strong tendency to cause cutaneous skin reactions, such as stinging and discomfort, when used as a leave-on emollient. ${ }^{24,25}$ Repeated application of AC over 28 days has been reported to cause numerous untoward effects at the cellular and molecular level, including decreased stratum corneum thickness and an increase in transepidermal water loss, ${ }^{26}$ as well as increased desquamatory and inflammatory protease activity. ${ }^{27}$ However, following the 7-day treatment regimen used in our study, no adverse signs or symptoms were visible for either DB gel or AC.

By employing a study design that combines both objective instrumental measurements of skin hydration as well as investigator and patient subjective assessments of product performance and acceptability under conditions simulating normal clinical use, we have demonstrated therapeutically important differences between two commonly prescribed emollient preparations. Possible limitations of this study include the short treatment period of 7 days and the three times daily treatment regimen, because in practice emollients tend to be used for long periods and in variable frequencies/ quantities.

\section{Disclosure}

This study was carried out independently by Reading Scientific Services Ltd, Reading, UK, and was funded by Dermal Laboratories Ltd, Hitchin, UK.

\section{References}

1. National Institute for Health and Clinical Excellence. Atopic eczema in children - management of atopic eczema in children from birth up to the age of 12 years. Available at: http://www.nice.org.uk/nicemedia/pdf/ CG057FullGuideline.pdf. Accessed May 30, 2012.

2. Lodén M. The skin barrier and use of moisturizers in atopic dermatitis. Clin Dermatol. 2003;21:145-157.
3. Watkins P. Using emollients to restore and maintain skin integrity. Nurs Stand. 2008;22:51-57.

4. Cork MJ. The importance of complete emollient therapy. Medicine Matters in Primary Care. 2007;142:1-8.

5. Rawlings AV, Canestrari DA, Dobkowski B. Moisturizer technology versus clinical performance. Dermatol Ther. 2004;17:49-56.

6. Cork MJ, Carr J, Young S, Holden C. Using emollients for eczema. Br J Dermatol Nurs. 2003;7:6-7.

7. Sidbury R, Poorsattar S. Pediatric atopic dermatitis: should we treat it differently? Dermatol Ther. 2006;19:83-90.

8. Ersser S, Maguire S, Nicol N. A best practice statement for emollient therapy. Dermatol Nurs. 2007;6:4-19.

9. Clark C. How to choose a suitable emollient. Pharm J. 2004;273: 351-353.

10. Simpson EL. Atopic dermatitis prevention. Dermatol Ther. 2006;19: $108-117$.

11. Van Neste D. Comparative study of normal and rough human skin hydration in vivo: Evaluation with four different instruments. J Dermatol Sci. 1991;2:119-124.

12. Girard P, Beraud A, Sirvent A. Study of three complementary techniques for measuring cutaneous hydration in vivo in human subjects: NMR spectroscopy, transient thermal transfer and corneometry-application to xerotic skin and cosmetics. Skin Res Technol. 2000;6:205-213.

13. Holm EA, Wulf HC, Thomassen L, Jemec GB. Instrumental assessment of atopic eczema: Validation of transepidermal water loss, stratum corneum hydration, erythema, scaling, and edema. J Am Acad Dermatol. 2006;55:772-780.

14. Lodén M, Hagforsen E, Lindberg M. The presence of body hair influences the measurement of skin hydration with the corneometer. Acta Derm Venereol. 1995;75:449-450.

15. Voegeli D. The vital role of emollients in the treatment of eczema. Br J Nurs. 2011;20:74-80.

16. Okamoto T, Inoue H, Anzai S, Nakajima H. Skin-moisturizing effect of polyols and their absorption into human stratum corneum. J Cosmet Sci. 1997;49:39-67.

17. Fluhr JW, Darlenski R, Surber C. Glycerol and the skin: holistic approach to its origin and functions. Br J Dermatol. 2008;159:23-34.

18. Lockhead RY, Henker WJ, Castaneda JY. Creams and lotions documentary. Cosmet Toiletries. 1986;101:125-138.

19. Wynne A, Whitefield M, Dixon AJ, Anderson S. An effective, cosmetically acceptable, novel hydro-gel emollient for the management of dry skin conditions. J Dermatol Treat. 2002;13:61-66.

20. Bremecker KD, Koch B, Krause W, Neuenroth L. Application-triggered drug release from an o/w-emulsion. Pharm Ind. 1992;54:182-185.

21. Cork MJ. The importance of skin barrier function. J Dermatol Treat. 1997;8:S7-S13.

22. Aslam A. Children's preference in selecting an emollient of their choice. Br J Dermatol. 2009;161 Suppl 1:116.

23. Lee E, An S, Choi D, Moon S, Chang I. Comparison of objective and sensory skin irritations of several cosmetic preservatives. Contact Dermatitis. 2007;56:131-136.

24. Cork MJ, Danby S. Skin barrier breakdown: a renaissance in emollient therapy. Br J Nurs. 2009;18:872-877.

25. Cork MJ, Timmins J, Holden C, et al. An audit of adverse drug reactions to aqueous cream in children with atopic eczema. Pharm J. 2003;271:747-748.

26. Tsang M, Guy RH. Effect of Aqueous Cream BP on human stratum corneum in vivo. Br J Dermatol. 2010;163:954-958.

27. Mohammed D, Matts PJ, Hadgraft J, Lane ME. Influence of Aqueous Cream BP on corneocyte size, maturity, skin protease activity, protein content and transepidermal water loss. Br J Dermatol. 2011;164: 1304-1310. 


\section{Publish your work in this journal}

Clinical, Cosmetic and Investigational Dermatology is an international, peer-reviewed, open access, online journal that focuses on the latest clinical and experimental research in all aspects of skin disease and cosmetic interventions. All areas of dermatology will be covered; contributions will be welcomed from all clinicians and basic science researchers globally. This journal is indexed on CAS. The manuscript management system is completely online and includes a very quick and fair peer-review system, which is all easy to use. Visit http://www.dovepress.com/testimonials.php to read real quotes from published authors.

Submit your manuscript here: http://www.dovepress.com/clinical-cosmetic-and-investigational-dermatology-journal 